\title{
Gambaran aritmia pada pasien penyakit jantung koroner di RSUP Prof. Dr. R. D. Kandou Manado periode 1 Januari 2015 - 31 Desember 2015
}

\author{
${ }^{1}$ Cathleen S. Kalangi \\ ${ }^{2}$ Edmond L. Jim \\ ${ }^{2}$ Victor F. F. Joseph
}

\author{
${ }^{1}$ Kandidat Skripsi Fakultas Kedokteran Universitas Sam Ratulangi Manado \\ ${ }^{2}$ Bagian Kardiologi Fakultas Kedokteran Unversitas Sam Ratulangi Manado \\ Email: cathleenkalangi@gmail.com
}

\begin{abstract}
Arrhythmia is an abnormal heart rhythm which refer to every disturbance in frequency, regularity, original location or electrical impulses conduction of the heart. Ischemic myocardium characterized by ionic and biochemical alterations creates an unstable electrical substrate capable of initiating and sustaining arrhythmias, meanwhile infarction creates areas of electrical inactivity and blocks conduction, which also promotes arrhythmogenesis. This study was aimed to obtain the description of arrhythmias in coronary artery disease patients at Prof. Dr. R. D. Kandou Hospital Manado from 1 January 2015 to 31 December 2015. This was a descriptive retrospective study. There were 101 data of patients with Coronary Artery Disease (CAD) associated with arrhythmia, as follows: 57 cases $(56 \%)$ of Stable Angina Pectoris (SAP), 6 cases (6\%) of Old Myocardial Infarction (OMI), 16 cases (16\%) of Unstable Angina Pectoris (UAP), 20 cases (20\%) of Non ST Segment Elevation Myocardial Infarction (NSTEMI), and 2 cases (2\%) of ST Segment Elevation Myocardial Infarction (STEMI). The majority of cases were males (66\%) and aged 51-60 years old (35\%). There were 62 cases (41\%) of CAD patients associated with arrhythmia that had hypertension as the highest risk factor and 19 cases (12\%) for smoker as the lowest risk factor. The highest number of patients was Angina Pectoris Stabil (APS), and the dominant arrhythmia was Premature Ventricular Contraction (PVC).
\end{abstract}

Keywords: description, arrhythmia, coronary artery disease

\begin{abstract}
Abstrak: Aritmia merupakan gangguan irama jantung yang merujuk kepada setiap gangguan frekuensi, regularitas, lokasi asal atau konduksi impuls listrik jantung. Iskemik miokardium ditandai dengan perubahan ion dan biokimiawi, mengakibatkan aktivitas listrik yang tidak stabil yang memicu dan mempertahankan aritmia, dan infark menciptakan daerah aktif dan blok konduksi listrik, yang juga memromosikan aritmogenesis. Penelitian ini bertujuan untuk mengetahui gambaran aritmia pada pasien penyakit jantung koroner (PJK) di RSUP Prof. Dr. R. D. Kandou Manado periode 1 Januari 2015-31 Desember 2015. Jenis penelitian ialah deskriptif retrospektif. Hasil penelitian mendapatkan 101 data pasien PJK yang mengalami aritmia, diantaranya Angina Pektoris Stabil (APS) 57 kasus (56\%), Old Myocardial Infarction (OMI) 6 kasus (6\%), Unstable Angina Pectoris (UAP) 16 kasus (16\%), Non ST Segment Elevation Myocardial Infarction (NSTEMI) 20 kasus (20\%), dan ST Segment Elevation Myocardial Infarction (STEMI) 2 kasus (2\%). Mayoritas kasus ialah jenis kelamin laki-laki (66\%), usia 51-60 tahun (35\%). Faktor risiko tertinggi pada pasien PJK dengan aritmia ialah hipertensi $(41 \%)$ dan terendah ialah merokok (12\%). Kasus tertinggi ialah APS, dengan aritmia terbanyak ialah Premature Ventricular Contraction (PVC),
\end{abstract}

Kata kunci: gambaran, aritmia, penyakit jantung koroner 
Aritmia atau disritmia merupakan gangguan irama jantung yang merujuk kepada setiap gangguan frekuensi, regularitas, lokasi asal atau konduksi impuls listrik jantung. ${ }^{1}$

Angka kejadian aritmia akan meningkat dengan bertambahnya usia. Diperkirakan, populasi geriatrik (lansia) akan mencapai $11,39 \%$ di Indonesia atau 28 juta orang di Indonesia pada tahun 2020. Makin bertambah usia, persentase kejadian aritmia makin meningkat, yaitu $70 \%$ pada usia 65-85 tahun dan $84 \%$ diatas 85 tahun. $^{2}$

Penyakit jantung koroner (PJK) telah menjadi penyebab kematian utama di Indonesia. Hasil Riset Kesehatan Dasar (RISKESDAS) Nasional tahun 2013, menunjukkan prevalensi PJK berdasarkan wawancara terdiagnosis dokter (D) di Indonesia sebesar $0,5 \%$, dan berdasarkan terdiagnosis dokter atau gejala (D/G) sebesar $1,5 \%$. Prevalensi PJK berdasarkan terdiagnosis dokter (D) tertinggi Sulawesi Tengah $(0,8 \%)$ diikuti Sulawesi Utara, DKI Jakarta, dan Aceh masing-masing 0,7\% sedangkan prevalensi PJK menurut diagnosis atau gejala tertinggi (D/G) di Nusa Tenggara Timur (4,4\%), diikuti Sulawesi Tengah $(3,8 \%)$, Sulawesi Selatan $(2,9 \%)$, dan Sulawesi Barat $(2,6 \%){ }^{3}$

Prevalensi (PJK) berdasarkan wawancara yang didiagnosis dokter serta yang didiagnosis dokter atau gejala meningkat seiring dengan bertambahnya usia, tertinggi pada kelompok usia 65-74 tahun, yaitu $2,0 \%$ dan $3,6 \%$, menurun sedikit pada kelompok usia $\geq 75$ tahun. Prevalensi PJK yang didiagnosis dokter maupun berdasarkan diagnosis dokter atau gejala lebih tinggi pada perempuan $(0,5 \%$ dan $1,5 \%)$. Prevalensi PJK lebih tinggi pada masyarakat tidak bersekolah dan tidak bekerja. $^{3}$

Data epidemiologi yang diperoleh dari New England Medical Journal (2001) menyebutkan bahwa kelainan struktur arteri koroner merupakan penyebab $80 \%$ gangguan irama jantung yang dapat berakhir dengan kematian mendadak. ${ }^{4}$

Sampai saat ini belum ada data mengenai aritmia pada pasien PJK di
RSUP Prof. DR. R. D. Kandou Manado. Penelitian ini bertujuan untuk mengetahui gambaran aritmia pada pasien PJK di RSUP Prof. Dr. R. D. Kandou Manado pariode 01 Januari 2015 sampai 31 Desember 2015.

\section{METODE PENELITIAN}

Jenis penelitian ini ialah deskriptif retrospektif dengan cara mengumpulkan data sekunder dari rekam medik selama periode 2015. Penelitian dilakukan di Bagian Rekam Medik Cardiovaskular and Brain Center (CVBC) RSUP Prof. Dr. R. D. Kandou Manado. Populasi dari penelitian ialah semua pasien yang datang di CVBC sedangkan sampel penelitian ialah pasien PJK dengan aritmia. Kriteria inklusi antara lain pasien yang didiagnosis sebagai PJK dengan aritmia, usia >18 tahun, dan aritmia yang terekam di EKG. Kriteria eksklusi ialah pasien dengan hipertiroid, gangguan elektrolit, penyakit paru obstruktif kronik (PPOK), dan chronic kidney disease (CKD) yang memiliki aritmia. Variabel penelitian ialah PJK, aritmia, usia, jenis kelamin, hipertensi, dislipidemia, diabetes melitus dan merokok. Penelitian ini dilakukan dengan cara mengumpulkan data rekam medik. Data diolah secara manual, disaji-kan dalam bentuk tulisan dan diagram serta dianalisis berdasarkan hasil persentase.

\section{HASIL PENELITIAN}

Berdasarkan penelitian yang dilakukan di CVBC RSUP Prof. Dr. R. D. Kandou Manado, didapatkan jumlah keseluruhan pasien PJK sebanyak 376 kasus dan yang mengalami aritmia sebanyak 119 kasus. Dari 119 kasus tersebut, yang termasuk dalam kriteria eksklusi sebanyak 18 kasus, diantaranya 6 kasus congestive heart failure (CHF), 4 kasus CKD, 5 kasus COPD, dan 3 kasus gangguan keseimbangan elektrolit, sehingga data rekam medik yang dapat dijangkau ialah 101 kasus (26,9\%).

Distribusi kasus aritmia berdasarkan jenis kelamin dari total 101 kasus, didapatkan laki-laki 67 kasus (66\%) dan perempuan 34 kasus (34\%) (Gambar 1). 


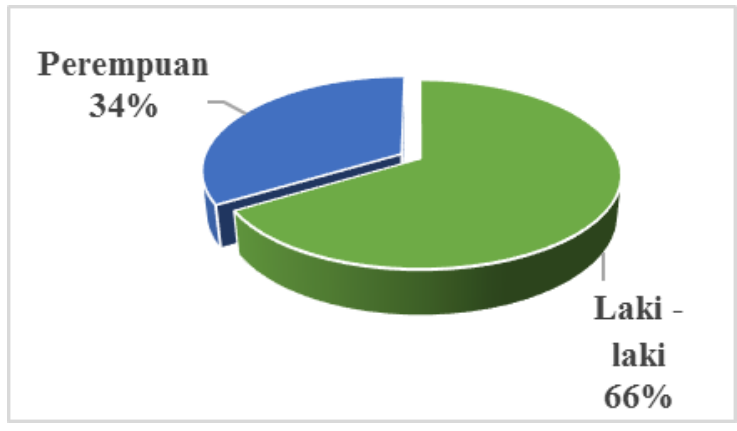

Gambar 1. Distribusi kasus aritmia berdasarkan jenis kelamin

Distribusi kasus aritmia berdasarkan usia dari 2 total 101 kasus, didapatkan 1 kasus (1\%) usia 21-30 tahun, 2 kasus (2\%) usia 3140 tahun, 13 kasus (13\%) usia 41-50 tahun, 36 kasus $(35 \%)$ usia 51-60 tahun, 29 kasus (29\%) usia 61-70 tahun, 19 kasus (19\%) usia 71-80 tahun, dan 1 kasus (1\%) usia >80 tahun.

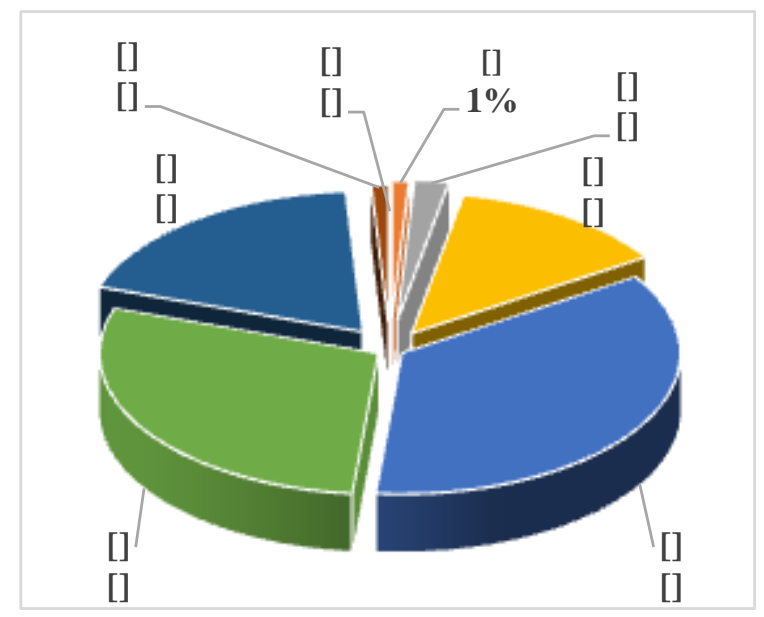

Gambar 2. Distribusi kasus aritmia berdasarkan usia

Distribusi kasus aritmia berdasarkan klasifikasi diagnosis PJK pada diagram 3 dengan total 101 kasus, didapatkan 57 kasus (56\%) Angina Pektoris Stabil (APS), 6 kasus $(6 \%)$ Old Myocardial Infarction (OMI), 16 kasus (16\%) Unstable Angina Pectoris (UAP), 20 kasus (20\%) Non ST Segment Elevation Myocardial Infarction (NSTEMI), dan 2 kasus (2\%) ST Segment Elevation Myocardial Infarction (STEMI).

Distribusi kasus aritmia berdasarkan APS pada Gambar 4 dengan total 57 kasus, didapatkan 12 kasus (21\%) sinus bradi- kardia, 6 kasus (11\%) sinus takikardia, 8 kasus (14\%) fibrilasi atrium, 1 kasus (2\%) Supraventricular Tachycardia (SVT), 12 kasus (21\%) Premature Ventricular Contraction (PVC), 7 kasus (12\%) Left Bundle Branch Block (LBBB), 7 kasus (12\%) Right Bundle Branch Block (RBBB), 4 kasus (7\%) AV blok, dan untuk jenis aritmia lainnya tidak didapatkan kasus $(0 \%)$.

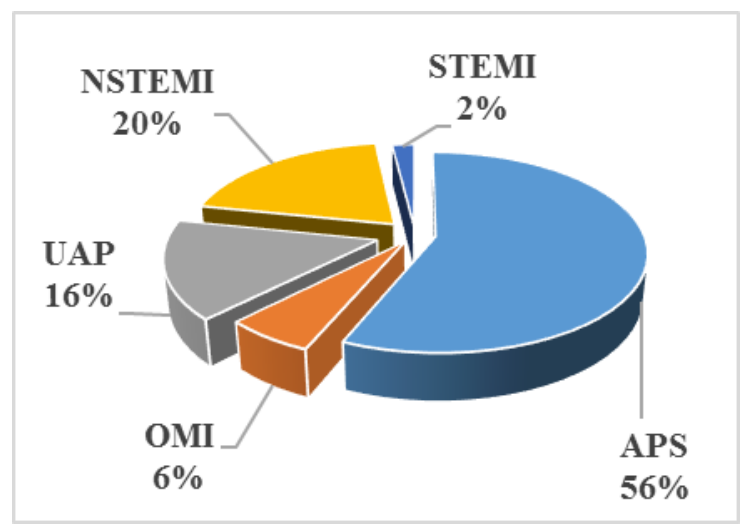

Gambar 3. Distribusi aritmia berdasaarkan klasifikasi diagnosis PJK

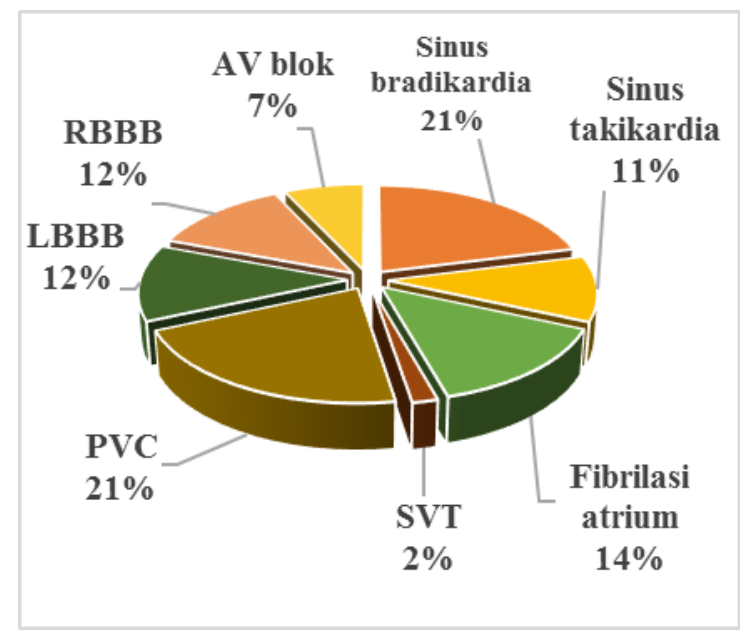

Gambar 4. Distribusi aritmia berdasarkan APS

Distribusi kasus aritmia berdasarkan Old Myocardial Infarction (OMI) pada diagram 5 dengan jumlah total 6 kasus, didapatkan 1 kasus (16\%) sinus takikardia, 1 kasus (17\%) fibrilasi atrium, 2 kasus (33\%) Premature Ventricular Contraction (PVC), 1 kasus (17\%) Supraventricular Tachycardia (SVT), 1 kasus (17\%) Ventricular Tachycardia (VT), dan untuk 
jenis aritmia lainnya tidak didapatkan kasus $(0 \%)$.

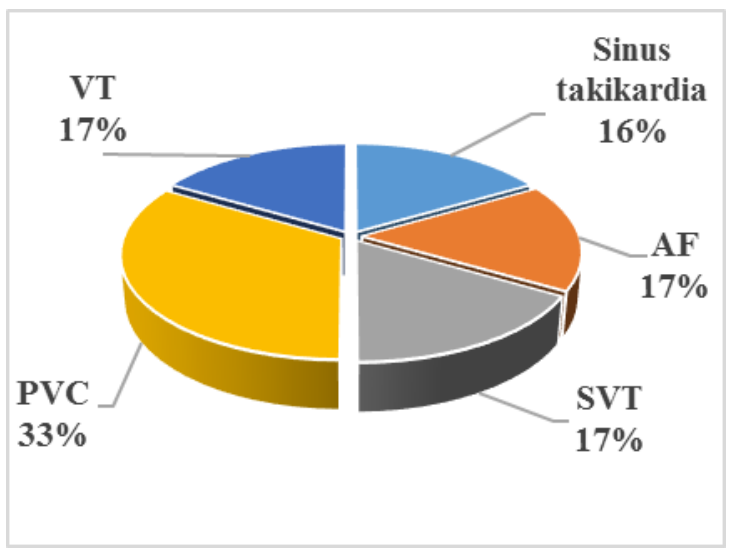

Gambar 5. Distribusi aritmia berdasarkan OMI

Distribusi kasus aritmia berdasarkan Unstable Angina Pectoris (UAP) pada diagram 6 dengan jumlah total 16 kasus, didapatkan 1 kasus (7\%) sinus bradikardia, 1 kasus (6\%) atrial flutter, 4 kasus (25\%) fibrilasi atrium, 4 kasus (25\%) Premature Ventricular Contraction (PVC), 1 kasus (6\%) Left Bundle Branch Block (LBBB), 4 kasus (25\%) (RBBB), 1 kasus (6\%) AV blok, dan untuk jenis aritmia lainnya tidak didapatkan kasus $(0 \%)$.

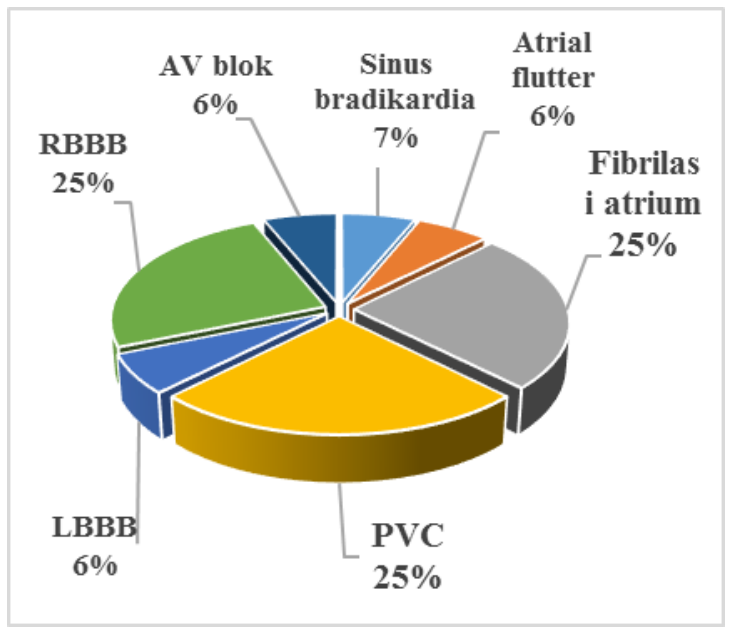

Gambar 6. Distribusi aritmia berdasarkan Unstable Angina Pectoris (UAP)

Distribusi kasus aritmia berdasarkan Non ST Elevation Myocardial Infarction (NSTEMI) pada diagram 7 dengan jumlah total 20 kasus, didapatkan 2 kasus (10\%) sinus bradikardia, 1 kasus $(5 \%)$ sinus takikardia, 2 kasus (10\%) fibrilasi atrium, 6 kasus (30\%) SVT, 3 kasus (15\%) PVC, 1 kasus (5\%) VT, 1 kasus (5\%) irama idioventrikel dipercepat, 1 kasus (5\%) LBBB, 2 kasus (10\%) RBBB, 1 kasus (5\%) AV blok, sedangkan untuk jenis aritmia lainnya tidak didapatkan kasus $(0 \%)$.

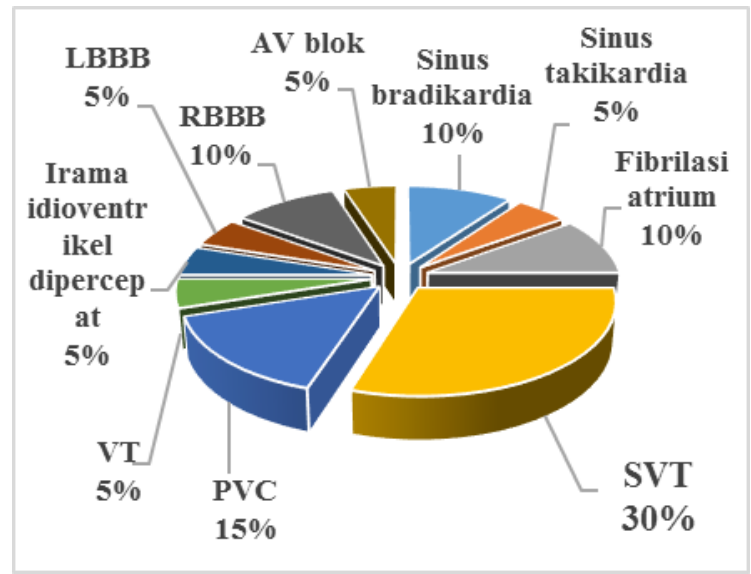

Gambar 7. Distribusi aritmia berdasarkan NSTEMI

Distribusi kasus aritmia berdasarkan ST Segment Elevation Myocardial Infarction (STEMI) (Gambar 8) dengan jumlah total 2 kasus, didapatkan 1 kasus (50\%) sinus takikardia, 1 kasus $(50 \%) \mathrm{AV}$ blok, dan untuk jenis aritmia lainnya tidak didapatkan kasus $(0 \%)$.

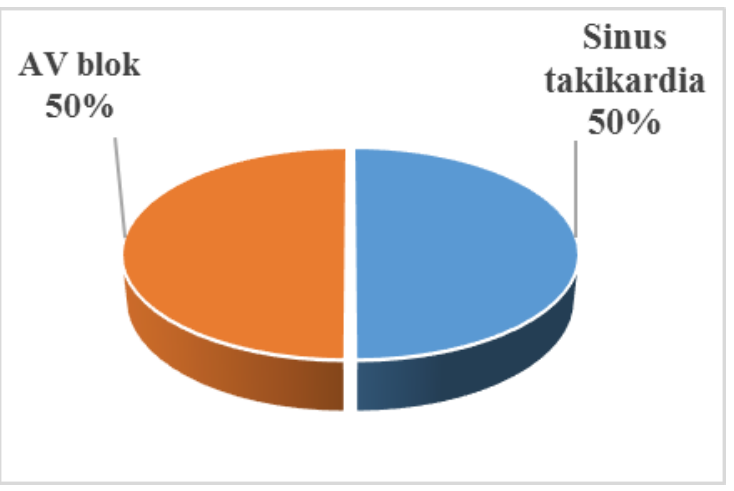

Gambar 8. Distribusi aritmia berdasarkan STEMI

Distribusi kasus aritmia berdasarkan klasifikasi aritmia (Gambar 9) didapatkan 24 kasus $(23 \%)$ aritmia yang berasal dari sinus, 24 kasus (24\%) aritmia supraventrikular, 24 kasus (24\%) aritmia ventrikel, 9 kasus (9\%) LBBB, 13 kasus (13\%) RBBB, 7 kasus (7\%) AV Blok, 
sedangkan untuk irama reetrant tidak didapatkan kasus $(0 \%)$.

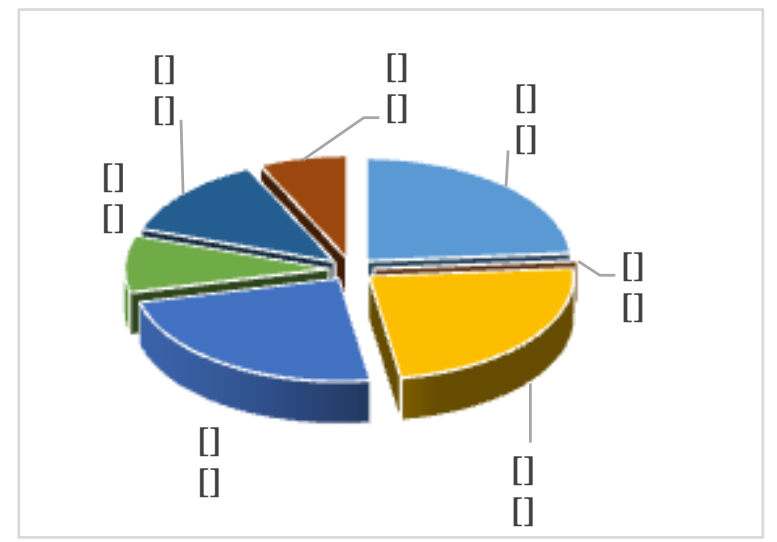

Gambar 9. Distribusi kasus aritmia berdasarkan klasifikasi aritmia

Distribusi kasus aritmia berdasarkan faktor risiko pada diagram 10 dengan total 101 kasus, didapatkan 62 kasus (41\%) hipertensi, 42 kasus (27\%) dislipidemia, 30 kasus $(20 \%)$ diabetes melitus dan 19 kasus (12\%) merokok.

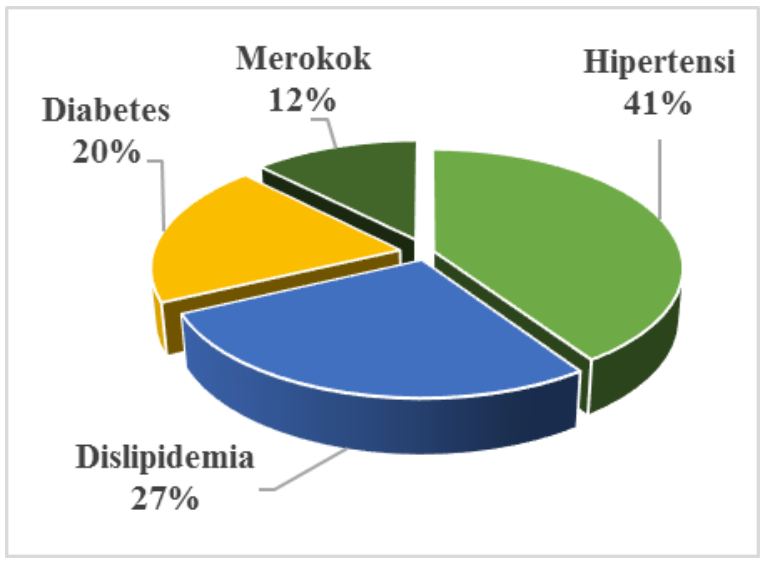

Gambar 10. Distribusi aritmia berdasarkan faktor risiko

\section{BAHASAN}

Dari hasil penelitian yang telah dilakukan pada bulan September sampai November di CVBC RSUP Prof. Dr. R. D. Kandou Manado periode 1 Januari 2015 sampai 31 Desember 2015 ditemukan 101 kasus $(26,9 \%)$ PJK yang mengalami aritmia.

Hasil penelitian total 101 kasus aritmia berdasarkan jenis kelamin didapatkan prevalensi laki-laki (66\%) lebih tinggi dibandingkan perempuan (34\%). Hal ini sejalan dengan penelitian yang dilakukan di Poliklinik Kardiologi RSUP Dr. Mohammad Hoesin Palembang 2012, yang menunjukkan bahwa prevalensi laki-laki lebih tinggi dibandingkan perempuan, dengan hasil 30 orang laki-laki $(72,9 \%)$ dan 13 orang $(27,1 \%)$ perempuan. ${ }^{5}$ Distribusi laki-laki lebih tinggi disebabkan oleh faktor risiko seperti gaya hidup yang tidak sehat, sedangkan perempuan disebabkan oleh faktor hormonal, terutama perempuan post menopause karena menurunnya kadar estrogen. Salah satu fungsi dari estrogen ialah faktor proteksi pembuluh darah. ${ }^{6}$

Hasil penelitian kasus aritmia berdasarkan usia, didapatkan kasus yang menempati posisi pertama ialah usia 51-60 tahun (35\%), diikuti usia 61-70 tahun (29\%), usia 71-80 tahun (19\%), dan usia 80 tahun $(1 \%)$. Penelitian yang dilakukan di RSUP Dr. Kariadi Semarang menunjukkan bahwa aritmia pada PJK paling banyak terjadi pada usia >45 tahun. Hasil ini sejalan dengan hasil penelitian yang ditemukan, yaitu usia 51-60 tahun. $^{7}$ Berbeda dengan penelitian Thaler $^{1}$ yang mengatakan bahwa kejadian aritmia akan meningkat seiring dengan bertambahnya usia yang mendapatkan ditemukan jumlah kasus menurun pada usia 61-70 tahun, 7180 tahun dan usia >80 tahun; hal ini disebabkan karena tingginya angka mortalitas.

Dari 101 kasus pasien PJK yang mengalami aritmia dengan prevalensi tertinggi ialah APS 57 kasus (56\%), NSTEMI 20 kasus (20\%), UAP 16 kasus (16\%), OMI 6 kasus (6\%), dan prevalensi terendah adalah STEMI 2 kasus (2\%).

Distribusi kasus aritmia tertinggi pada APS ialah sinus bradikardia dan PVC dengan jumlah masing-masing 12 kasus $(21 \%)$ dan aritmia yang terendah adalah SVT 1 kasus (2\%). Bradikardia ringan dan tanpa gejala tidak memerlukan terapi, namun menjadi masalah jika sudah menimbulkan gejala dan tanda. ${ }^{8}$ Beberapa aritmia yang sering terjadi pada atlet yang menyebabkan terjadinya pembesaran jantung ialah, sinus bradikardia, perubahan segmen ST dan gelombang $\mathrm{T}$ yang non 
spesifik, RBBB inkomplit, AV blok derajat 1 dan aritmia supraventrikular. ${ }^{1,9}$

Distribusi kasus aritmia tertinggi pada OMI ialah PVC 2 kasus (33\%), dan aritmia terendah ialah sinus takikardia, fibrilasi atrium, SVT dan VT yang memiliki jumlah kasus masing-masing 1 kasus (17\%). VT yang berlangsung terus menerus merupakan keadaan kegawatdaruratan yang menandakan henti jantung. ${ }^{1}$

Distribusi kasus aritmia tertinggi pada UAP ialah PVC, fibrilasi atrium, dan RBBB dengan jumlah masing-masing 4 kasus $(25 \%)$ dan aritmia terendah adalah sinus bradikardia, atrial flutter, LBBB, dan AV blok yang memiliki jumlah masingmasing 1 kasus (6\%). RBBB terjadi pada pasien yang memiliki penyakit jantung yang mendasari seperti hipertrofi ventrikel kanan, kardiomiopati, penyakit jantung kongenital, atau penyakit jantung rematik. LBBB terjadi pada penyakit jantung koroner dan kardiomiopati. ${ }^{10}$ Atrial flutter merupakan tanda awal dari penyakit jantung koroner, gejala dan tanda bergantung pada respon ventrikular. Fibrilasi atrium adalah jenis aritmia yang sering terjadi pada sindrom koroner akut, gagal jantung, penyakit katup mitral atau trikuspid. ${ }^{11}$

Distribusi kasus aritmia tertinggi pada NSTEMI ialah SVT 6 kasus (30\%), PVC 3 kasus (15\%), dan sinus bradikardia, fibrilasi atrium, RBBB dengan jumlah kasus yang sama, masing-masing 2 kasus (10\%), dan kasus yang terendah adalah VT, irama idioventrikel dipercepat, LBBB, dan AV blok masing-masing 1 kasus (5\%). SVT merupakan aritmia yang diderita sekitar $1 \%$ populasi, paling sering ditemukan dalam kehidupan sehari-hari. ${ }^{12}$

Distribusi kasus aritmia tertinggi pada STEMI ialah sinus takikardia dan AV blok masing-masing 1 kasus (50\%), dan untuk aritmia jenis lainnya tidak didapatkan kasus $(0 \%)$. Infark miokardial anterior sering mengenai daerah yang luas dari miokardium dan dapat menimbulkan aritmia serperti AV blok derajat 2 tipe II dan AV blok derajat 3. Infark miokardial inferior sering menimbulkan sinus bradikardia dan AV blok. ${ }^{10}$

Hasil penelitian kasus aritmia berdasarkan klasifikasi aritmia, didapatkan kasus tertinggi adalah aritmia yang berasal dari sinus, aritmia supraventrikular dan aritmia ventrikel dengan prevalensi masing-masing adalah 24 kasus (24\%), diikuti oleh RBBB 13 kasus (13\%), LBBB 9 kasus (9\%), AV Blok 7 kasus (7\%) dan kasus yang terendah adalah irama reetrant $(0 \%)$. Dari distribusi aritmia yang berasal dari sinus, didapatkan prevalensi tertinggi adalah sinus bradikardia yaitu sebanyak 15 kasus (65\%). Disbribusi aritmia supraventrikular dengan prevalensi tertinggi ialah AF 15 kasus (63\%). Distribusi aritmia ventrikel dengan prevalensi tertinggi adalah PVC 21 kasus (88\%). Dari data tersebut dapat dilihat bahwa aritmia yang paling sering terjadi ialah PVC, ini berbeda dengan hasil jurnal kardiologi Indonesia yang mengatakan bahwa AF merupakan aritmia jantung yang paling sering terjadi dengan bertambahnya usia. $^{13}$ dan juga menurut Theler ${ }^{1}$ mengatakan bahwa fibrilasi atrium jauh lebih sering ditemui dan merupakan jenis aritmia terus-menerus yang paling banyak dijumpai di masyarakat.

Hasil penelitian kasus aritmia pada PJK berdasarkan faktor risiko, didapatkan prevalensi tertinggi ialah hipertensi 62 kasus (41\%), dislipidemia 42 kasus (27\%), diabetes melitus 30 kasus (20\%), dan merokok 19 kasus (12\%). Hipertensi ialah faktor risiko penyakit kardiovaskular. Orang dengan hipertensi mempunyai risiko terkena PJK 5x lebih besar. ${ }^{3}$ Hipertensi merupakan penyebab kematian nomor satu di dunia, disusul merokok dan dislipidemia. Hipertensi menyebabkan dinding ventrikel kiri menjadi kaku dan tebal, sehingga dapat mengubah jalur impuls listrik di jantung. Hipertensi merupakan salah satu faktor risiko mayor untuk terjadinya penyakit kardiovaskular yang akan meningkat dengan bertambahnya usia. ${ }^{14} \mathrm{Hal}$ ini sesuai dengan hasil penelitian yang ditemukan bahwa faktor risiko terbanyak dan utama ialah hipertensi.

Keterbatasan dari penelitian ini ialah 
beberapa gambaran EKG pada data rekam medik yang sudah mulai pudar sehingga sulit untuk dilihat. Selain itu, referensi penelitian aritmia pada PJK secara spesifik masih sangat sedikit.

\section{SIMPULAN}

Berdasarkan hasil penelitian yang dilakukan di Cardiovaskular and Brain Center (CVBC) RSUP. Prof. Dr. R. D. Kandou Manado mengenai gambaran aritmia pada pasien penyakit jantung koroner dapat disimpulkan bahwa, Angina Pektoris Stabil (APS) merupakan kasus tertinggi dengan Premature Ventricular Contraction $(P V C)$ sebagai kasus aritmia terbanyak, dominan terjadi pada laki-laki, paling banyak terjadi pada usia antara 51-60 tahun dan hipertensi menjadi faktor risiko tertinggi.

\section{SARAN}

Untuk institusi data rekam medik agar dapat memaksimalkan proses penyimpanan data sehingga dapat mempermudah penelitian selanjutnya.

Dapat dilakukan penelitian tentang gambaran aritmia pada pasien penyakit jantung koroner (PJK) setiap tahun, agar dapat diperoleh data dari tahun ke tahun dan juga dapat dilihat perbandingannya.

Disarankan untuk masyarakat agar dapat menjaga gaya hidup yang sehat sehingga terhindar dari faktor risiko yang dapat menimbulkan (PJK).

\section{DAFTAR PUSTAKA}

1. Thaler MS. Satu-satunya Buku EKG yang Anda Perlukan (7th ed). Jakarta: EGC, 2013.

2. Evy. Gangguan irama jantung picu stroke. Kompas cyber media [online]; 2007. Available from URL: http: //www.64.203.71.11/veri/kesehatan/0707 /27/095136.htm
3. Kementrian kesehatan RI. Riset kesehatan dasar (RISKESDAS) 2013. Jakarta: badan Litbangkes, Depkes RI; 2013;91-2.

4. Huikari HV, Castellanos A, Meyrbug RJ. Sudden death due to cardiac arrhythmias. N Engl J Med; 2007. Available from: http://www.contentnejm.org/cgl/content/full/345/20/1473.ht $\mathrm{m}$.

5. Novriyanti ID, Usnizar F, Irwan. Pengaruh lama hipertensi terhadap penyakit jantung koroner di Poliklinik Kardiologi RSUP. Dr. Mohammad Hoesin Palembang 2012. Jurnal Kedokteran dan Kesehatan. 2014;1(1):57.

6. Price SA, Wilson LM. Patofisiologi Konsep Klinis Proses-proses Penyakit (6th ed). Jakarta: EGC; 2005;517-8.523,524.

7. Zahrawardani D, Herlambang $K$, Anggraheny $\mathbf{H}$. Analisis faktor risiko kejadian penyakit jantung koroner di RSUP. Dr. Kariadi Semarang. Jurnal Kedokteran Muhammadiyah. 2013;1(2):15.

8. Perhimpunan Dokter Spesialis Kardio-vaskular Indonesia. Bantuan hidup jantung lanjut ACLS Indonesia Edisi 2013. Jakarta: PERKI.

9. Dharma S. Pedoman praktis sistematika interpretasi EKG. Jakarta: EGC, 2007.

10. Jones, SA. ECG Success Exercises in ECG Interpretation. Philadelphis: F.A Davis company, 2005.

11. Perhimpunan dokter spesialis kardiovaskular Indonesia. Bantuan hidup jantung lanjut BCLS Indonesia Edisi 2013. Jakarta: PERKI

12. Setiati S, Alwi I. Buku Ajar Ilmu Penyakit Dalam Jilid I (6th ed). Jakarta: Interna Publishing, 2014; p. 1362.

13. Faizel O, Michael D, Gammage, Michael C, Sheppard. Jayne A. Franklyn. Cardiac dysrhythmias and thyroid dysfunction. J Clin Endocrinol. 2002;87(3):963-7.

14. Setiati S, Alwi I. Buku Ajar Ilmu Penyakit Dalam Jilid II. Jakarta: InternaPublishing, 2014; p. 1436, 1437, 1449, 1459, 2259. 